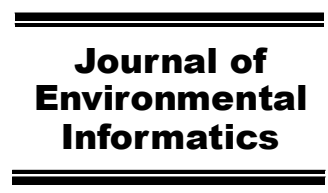

www.iseis.org/jei

\title{
Simultaneous Production Scheduling and Waste Management Optimization for an Oil Sands Application
}

\author{
E. Ben-Awuah ${ }^{1, *}$, T. Elkington ${ }^{1}$, H. Askari-Nasab ${ }^{2}$, and F. Blanchfield ${ }^{1}$ \\ ${ }^{I}$ Snowden Mining Industry Consultants, 87 Colin Street, West Perth WA 6005, Australia \\ ${ }^{2}$ School of Mining and Petroleum Engineering, University of Alberta, Alberta, Edmonton T6G 2W2, Canada
}

Received 25 September 2013; revised 27 March 2014; accepted 27 June 2014; published online 01 June 2015

\begin{abstract}
Mine planning for oil sands involves the integration of waste management into the long term production planning process. This ensures that while ore is provided for the processing plant, sufficient in-pit tailings containment areas are made available as dedicated disposal areas for backfilling. This enables the creation of a trafficable landscape at the earliest opportunity to facilitate progressive reclamation. Apart from being a regulatory requirement, this integration impacts directly on the profitability and sustainability of oil sands mining operations. This paper introduces a mixed integer linear programming mine planning framework that seeks to simultaneously determine the production schedule, dyke construction schedule and the backfilling schedule. Different waste management strategies were also investigated. The model generated a practical, smooth and uniform schedule for ore, dyke material and backfilling activities. The results show that for the case studies considered, increasing the number of in-pit tailings cells reduces the net present value of the mine as a result of a reduced operational flexibility. However, this strategy makes in-pit tailings storage areas available earlier in the mine life, and ensures an efficient use of in-pit storage areas required for sustainable operations.
\end{abstract}

Keywords: continuous backfilling, dyke construction, mine planning, mixed integer linear programming, oil sands mining, production scheduling, waste management optimization

\section{Introduction}

Oil sands mining is usually characterized by large open pits and tailings dams. These operations leave behind large reclamation areas. Over $80 \%$ of oil sands ore are ultimately deposited in tailings dams in the form of fine and coarse sand by-products. These sand by-products significantly increase in volume during processing generating environmental and regulatory concerns in terms of their storage. Regulations by Alberta Energy Resources and Conservation Board (Directive 074) (McFadyen, 2008) requires oil sands mining companies to develop integrated mine planning and waste management strategies for their in-pit and external tailings facilities. It is therefore important to develop mine plans that integrate production scheduling with waste management in an optimization framework that generates value and is sustainable. Sustainability for oil sands operations includes ensuring that in-pit storage areas are available on time and making an efficient use of this storage space. This ensures that the operation does not grind to a halt due to unavailable tailings storage areas and reclamation can start early in time. Optimization of this problem is quite a challenge in terms of mathematical formulations, computational power and speed. Applying ma-

\footnotetext{
* Corresponding author. Tel.: +1 705 6751151; fax: +1 7056754862 .

E-mail address: benawuah@ualberta.ca (E. Ben-Awuah).
}

ISSN: $1726-2135$ print/1684-8799 online

(C) 2015 ISEIS All rights reserved. doi:10.3808/jei.201500305 thematical programming models (MPMs) such as linear programming (LP), mixed integer linear programming (MILP) and goal programming (GP) with exact solution methods have proven to be robust. Solving MPMs with exact solution methods result in solutions within known limits of optimality. As the solution gets closer to optimality, it results in production schedules that generate higher net present value (NPV) than those obtained from heuristic optimization methods.

Though MPMs have been applied in mine production scheduling, little work has been done in terms of oil sands mine planning, which has a challenging scenario when it comes to waste management. It is our objective to develop an MILP model that simultaneously schedules for production material, dyke material and backfilling material in an integrated oil sands mine planning (IOSMP) framework. The MILP formulation maximizes the NPV of the operation, minimizes the dyke construction cost and maximizes the backfilling revenue through the cash flow from mining the production and dyke construction material, and backfilling the in-pit mined areas respectively. The production material cash flow is controlled by the revenue from mining ore and the cost of mining ore and waste. The dyke construction material cash flow is controlled by the extra cost of mining dyke material and sending it to the required destination. The in-pit backfilling cash flow is controlled by a pseudo revenue generated by backfilling the in-pit mined areas. This pseudo revenue is the savings generated from in-pit backfilling as compared to ex-pit waste management. Snowden's Evaluator software (Sn- 


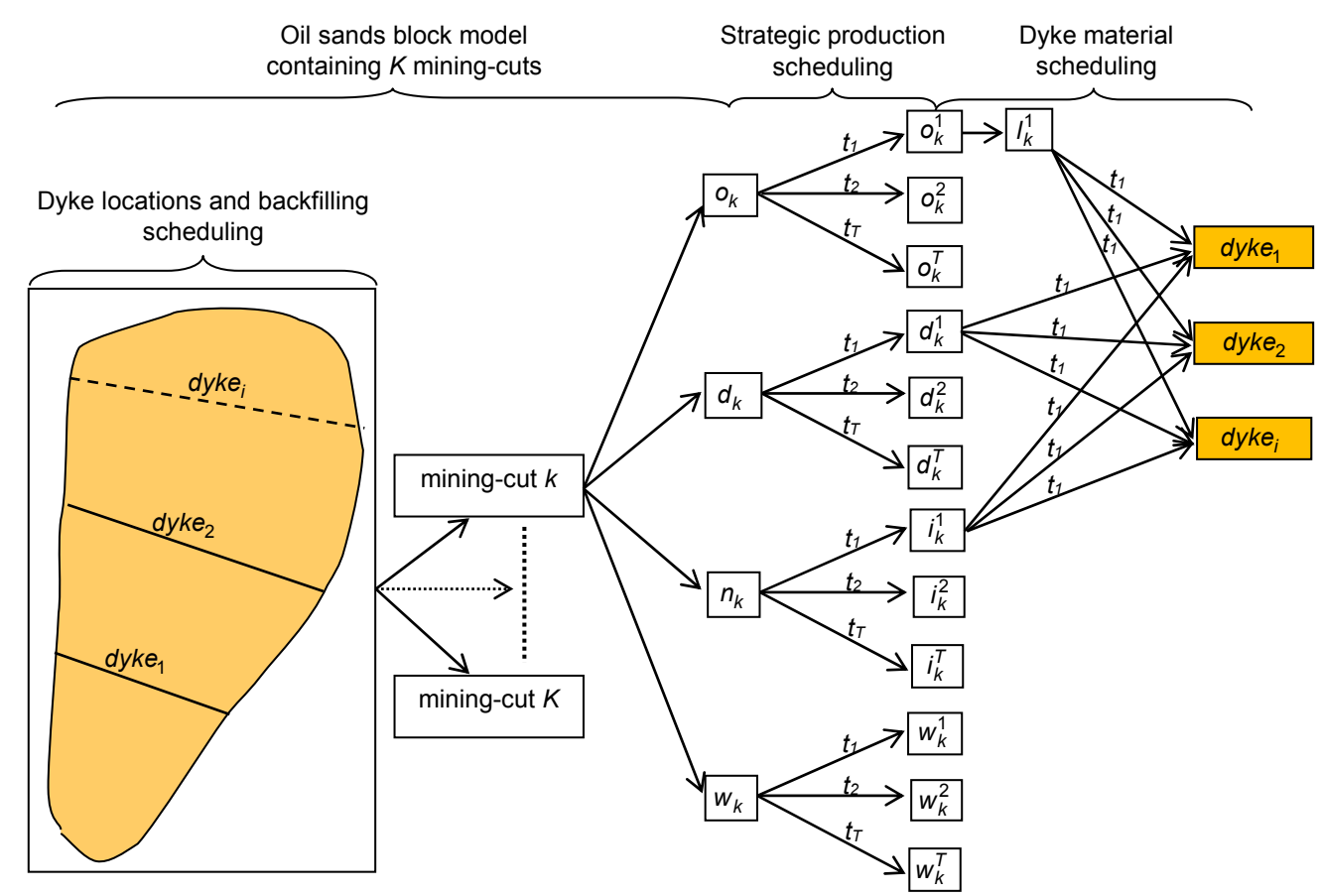

Figure 1. Schematic diagram of the problem definition showing strategic production, dyke material, dyke location and backfilling scheduling modified after Ben-Awuah and Askari-Nasab (2011).

owden Mining Industry Consultants, 2013) was chosen as the modeling platform for this research. Evaluator can be used for a wide range of mining scenarios with a user friendly graphical modeling interface that allows for great flexibility. It allows for material flow to be modeled for multiple sources, destinations and materials types while applying the required material stream flow constraints necessary to describe complex problems. Evaluator uses an optimization solver known as Gurobi (Gurobi Optimization, 2013) which is developed based on branch and cut optimization algorithm.

The rest of the paper is organized as follows. Section 2 outlines the general process of oil sands mining and material classification system used. Section 3 defines the IOSMP problem, while section 4 summarizes the literature on the application of mathematical programming models to the long term production planning problem. This is followed by a section on the application of MILP model for IOSMP problem. Section 6 outlines the concepts used in modeling the IOSMP problem and a case study presented in section 7 . The paper concludes in section 8 .

\section{Oil Sands Mining}

The oil sands mining system comprises of the removal of overburden material and the mining of McMurray formation. The overburden material includes muskeg/peat, the Pleistocene unit and the Clearwater formation. The muskeg/peat is barren and very wet in nature and once it is stripped, it is left for about 2 to 3 years to get it dry making it easier to handle. This material is stockpiled for future reclamation works required for all disturbed landscapes. The mining of the Pleistocene and Clearwater formation, which is classified as waste, is to enable the exposure of the ore bearing McMurray formation. Some of this material is used in the construction of dykes and are referred to as overburden dyke material. The dyke construction is for the development of tailings dam facilities constructed in-pit or expit in dedicated disposal areas.

The mining of the oil bearing McMurray formation follows after the removal of the overburden material. By the regulatory and technical requirements, the mineable oil sand should have about 7\% bitumen content (Dilay, 2001; Masliyah, 2010). All material satisfying this requirement is classified as ore and otherwise as waste. Some of this class of waste material are used for dyke construction and are referred to as interburden dyke material. The ore is sent directly to the processing plant. After processing the ore to extract bitumen, two main types of tailings are produced; fine and coarse tailings. The coarse tailings which can be used for dyke construction are referred to as tailings coarse sand dyke material. The fine tailings form the slurry which needs to be contained in the tailings facilities.

\section{Defining the IOSMP Problem}

As oil sands mining companies continue to commit themselves to sustainable mining, the urgency of generating and implementing sustainable waste management practices becomes evident. Together with the limitations in lease areas, it has become necessary to look into effective and efficient waste disposal planning system. In oil sands operations, the pit phase mining occurs simultaneously with the construction of in-pit dykes in the mined out areas of the pit and ex-pit dykes in designated areas outside the pit. These dykes are constructed to hold tailings that are produced during processing of the oil sands ore. 
The materials used in constructing these dykes come from the oil sands mining operation. The dyke materials are made up of overburden (OB), interburden (IB) and tailings coarse sand (TCS). Any material that does not qualify as ore or dyke material is sent to the waste dump.

The integrated oil sands planning problem can be categorized in four main parts:

a) Determining the order and time of extraction of ore, dyke material and waste to be removed from the designed pit shell that maximizes the Net Present Value (NPV) of the operation,

b) Determining the destination of dyke material that minimizes construction cost based on the construction requirements of the various dykes,

c) Determining the number and location of dykes that minimizes waste management cost, and

d) Generating a backfilling schedule that maximizes the in-pit tailings disposal strategy.

Prior to IOSMP, it is assumed that the material in the designed pit limit is discretized into a three-dimensional array of rectangular or cubical blocks called a block model. Attributes of the material in the block model such as rock types, densities, grades, or economic data are represented numerically (AskariNasab et al., 2011; Ben-Awuah and Askari-Nasab, 2011). Figure 1 shows the schematic diagram of the scheduling of an oil sands final pit block model containing $k$ mining-cuts. Miningcuts are clusters of blocks within the same level or mining bench that are grouped based on a similarity index defined using the attributes; location, grade, rock type and the shape of miningcuts that are created on the lower bench. In this research, an agglomerative hierarchical clustering algorithm which seeks to generate clusters with reduced mining-cut extraction precedences compared with other automated methods is used (Tabesh and Askari-Nasab, 2011). Each mining-cut $k$, is made up of ore $o_{k}$, OB dyke material $d_{k}$, IB dyke material $n_{k}$, and waste $w_{k}$. The material in each mining-cut is to be scheduled over $T$ periods depending on the goals and constraints associated with the mining operation. OB dyke material scheduled $d_{k}^{T}$, IB dyke material scheduled $n_{k}^{T}$, and TCS dyke material from the processed ore scheduled, $l_{k}^{T}$, must further be assigned to the dyke construction sites based on construction requirements. For period $t_{1}$, the dyke construction material required by site $i$ is $d y k e_{i}$. In addition, the final pit limit block model is divided into pushbacks. The material intersecting a pushback and a bench is known as a mining-panel. Each mining-panel contains a set of mining-cuts and is used to control the mine production operation sequencing.

The schedules generated for IOSMP drives the profitability and sustainability of an oil sands mining operation. The strategic production schedule controls the NPV of the operation while the dyke material, dyke location and backfilling schedules provide the platform for a robust waste management planning system. Previous attempts in solving the IOSMP problem with mathematical programming did not include a backfilling schedule in the optimization problem(Ben-Awuah, 2013; Ben-Awuah and Ask-
ari-Nasab, 2013). This places some limitations on the IOSMP optimization problem which can result in deviations from the optimal mining strategy. In large mining projects, such deviations can lead to major losses in revenue. In this study, we are seeking to optimize the production schedule with material destination being determined based on the mine economics, regulatory and operational requirements. The number and location of dykes will also be investigated as well as an effective backfilling schedule. This way the delicate balance between deciding on tailings dam cell sizes versus maximizing NPV and minimizing waste management cost can be evaluated.

\section{Summary of Literature Review}

The application of mathematical programming models (MPMs) to mining decision making problems has been a major research area since the 1960s. The challenge at the time included the availability of powerful personal computers and robust optimization solvers that could deal with the large problem sizes resulting from these applications. This led to extensive research on the application of MPMs like LP and MILP to the long term production planning problem. The inherent difficulty in implementing these models is that, they result in large scale optimization problems containing many binary and continuous variables. These are difficult to solve and may have lengthy solution times.

Previous researchers have made significant efforts in reducing the solution time associated with solving MPMs. Their models however, were not capable of dealing with large block model sizes or could not generate feasible practical mining strategies (Johnson, 1969; Gershon, 1983; Dagdelen, 1985; Akaike and Dagdelen, 1999; Ramazan, 2001; Caccetta and Hill, 2003; Ramazan and Dimitrakopoulos, 2004). These publications note that the size of the resulting LP and MILP models is a major problem because it contains too many binary and continuous variables. GP has also been explored in dealing with the long term production planning problem. It permits flexible formulation, specification of priorities among goals, and some level of interactions between the decision maker and the optimization process (Zeleny, 1980; Hannan, 1985). This led to its application to the long term production planning problem by Zhang et al. (1993), Chanda and Dagdelen (1995) and Esfandiri et al. (2004). They were however unable to practically implement their models due to the numerous mining production constraints and size of the optimization problem.

Recent implementation of MILP models with block clustering techniques were successfully undertaken for an iron ore deposit (Askari-Nasab et al., 2010; Askari-Nasab et al., 2011). It however lacks the framework for the implementation of an integrated mine planning and waste management system as is the case required for sustainable oil sands mining. Due to the strategy required for sustainable oil sands mining and the regulatory requirements from Directive 074, waste management is directly linked to the mine planning system (McFadyen, 2008; Askari-Nasab and Ben-Awuah, 2011; Ben-Awuah and AskariNasab, 2011; Ben-Awuah, 2013). Currently, oil sands waste disposal planning is managed as a post-production scheduling opti- 
mization activity. Consequently, the lack of an integrated sustainable oil sands mine production scheduling and waste disposal planning system in an optimization framework is a challenge. Modeling such an integrated mine planning system even adds more complexity to the long term production planning problem. Ben-Awuah et al. (2012) implemented a MILGP model for an integrated oil sands production scheduling and waste disposal planning system. The model takes into account multiple material types, elements and destinations, directional mining, waste management and sustainable practical mining strategies. The implementation of the MILGP model did not include assessment of backfilling strategies which forms an integral part of the IOSMP problem.

This paper presents scheduling models and tests on how to implement an MILP framework for an IOSMP problem with varying waste management strategies. The tests show that, varying waste management strategies have different impacts on NPV and waste management cost. Depending on the mining operation's environmental and reclamation policy as compared to its investment strategy, the appropriate IOSMP option may be suitable. An oil sands data set is used for the case study.

\section{MILP Model for IOSMP}

The IOSMP problem can be summarized as finding the time and sequence of extraction of ore, dyke material and waste mining-cuts to be removed from an open pit outline and sent to their respective destinations over the mine life, so that the NPV of the operation is maximized and waste management cost is minimized. The waste management includes dyke construction and backfilling activities. This requires an MILP formulation involving multiple mines, material types and destinations as well as pushbacks which ties into the waste management strategy for the oil sands operations. The production schedule is subject to a variety of technical, physical and economic constraints which enforce mining extraction sequence, mining and dyke construction capacities, blending requirements and backfilling strategy. The notations used in the formulation of the IOSMP problem have been classified as sets, indices, subscripts, superscripts, parameters and decision variables. An exhaustive list of these notations can be found in this section and in the Appendix.

The summary of economic data for each mining-cut known as economic mining-cut value is based on ore parcels within mining-cuts which could be mined selectively. The economic mining-cut value is a function of the value of the mining-cut based on the processing destination and the costs incurred in mining from a designated location and processing, and dyke construction at a specified destination. The cost of dyke construction is also a function of the location of the tailings facility being constructed and the type and quantity of dyke material used. The discounted economic mining-cut value for miningcut $k$ is equal to the discounted revenue obtained by selling the final product contained in mining-cut $k$ minus the discounted cost involved in mining mining-cut $k$ as waste minus the extra discounted cost of mining OB and IB dyke material, and generating TCS dyke material from mining-cut $k$ for a designated dyke construction destination. This can be summarized by Equ- ations (1) to (6). The concepts presented in Ben-Awuah and Askari-Nasab (2013) were used as the starting point of the development.

Discounted economic mining-cut value equals to discounted revenue minus discounted costs:

$d_{k}^{u, t}=v_{k}^{u, t}-q_{k}^{a, t}-p_{k}^{u, t}-m_{k}^{u, t}-h_{k}^{u, t}$

The variables in Equation (1) can be defined by Equations (2) to (6)

$$
\begin{aligned}
& v_{k}^{u, t}=\sum_{e=1}^{E} o_{k} \times g_{k}^{e} \times r^{u, e} \times\left(p^{e, t}-c s^{e, t}\right)-\sum_{e=1}^{E} o_{k} \times c p^{u, e, t} \\
& q_{k}^{a, t}=\left(o_{k}+d_{k}+n_{k}+w_{k}\right) \times c m^{a, t} \\
& p_{k}^{u, t}=d_{k} \times c k^{u, t} \\
& m_{k}^{u, t}=n_{k} \times c b^{u, t} \\
& h_{k}^{u, t}=l_{k} \times c t^{u, t}
\end{aligned}
$$

where:

$t \in\{1, \ldots, T\}$ index for scheduling periods.

$k \in\{1, \ldots, K\}$ index for mining-cuts.

$p \in\{1, \ldots, P\}$ index for mining-panels.

$e \in\{1, \ldots, E\}$ index for elements of interest in each mining-cuts.

$j \in\{1, \ldots, J\}$ index for phases (pushback).

$u \in\{1, \ldots, U\}$ index for possible destinations for materials.

$a \in\{1, \ldots, A\}$ index for possible mining locations (pits).

$d_{k}^{u, t}$ the discounted economic mining-cut value obtained by extracting mining-cut $k$ and sending it to destination $u$ in period $t$.

$v_{k}^{u, t}$ the discounted revenue obtained by selling the final products within mining-cut $k$ in period $t$ if it is sent to destination $u$, minus the extra discounted cost of mining all the material in mining-cut $k$ as ore from location $a$ and processing at destination $u$.

$q_{k}^{a, t}$ the discounted cost of mining all the material in miningcut $k$ in period $t$ as waste from location $a$.

$b_{p}^{a, t}$ the discounted cost of mining all the material in miningpanel $p$ in period $t$ as waste from location $a$. Each mining-panel $p$ contains its corresponding set of mining-cuts.

$p_{k}^{u, t}$ the extra discounted cost of mining all the material in mining-cut $k$ in period $t$ as overburden dyke material for construction at destination $u$.

$m_{k}^{u, t}$ the extra discounted cost of mining all the material in mining-cut $k$ in period $t$ as interburden dyke material for construction at destination $u$. 
$h_{k}^{u, t}$ the extra discounted cost of mining all the material in mining-cut $k$ in period $t$ as tailings coarse sand dyke material for construction at destination $u$.

$o_{k} \quad$ the ore tonnage in mining-cut $k$.

$d_{k}$ the overburden dyke material tonnage in mining-cut $k$.

$n_{k}$ the interburden dyke material tonnage in mining-cut $k$.

$w_{k}$ the waste tonnage in mining-cut $k$.

$l_{k} \quad$ the tailings coarse sand dyke material tonnage in miningcut $k$.

$g_{k}^{e}$ the average grade of element $e$ in ore portion of miningcut $k$.

$r^{u, e}$ the proportion of element $e$ recovered (processing recove-

ry) if it is processed at destination $u$.

$p^{e, t}$ the price of element $e$ in present value terms per unit of product.

$c s^{e, t}$ the selling cost of element $e$ in present value terms per unit of product.

$c p^{u, e, t}$ the extra cost in present value terms per tonne of ore for mining and processing at destination $u$.

$\mathrm{cm}^{a, t}$ the cost in present value terms of mining a tonne of waste in period $t$ from location $a$.

$c k^{u, t}$ the cost in present value terms per tonne of overburden dyke material for dyke construction at destination $u$.

$c b^{u, t}$ the cost in present value terms per tonne of interburden dyke material for dyke construction at destination $u$.

$c t^{u, t}$ the cost in present value terms per tonne of tailings coarse sand dyke material for dyke construction at destination $u$.

\subsection{The MILP Model for Optimizing Production Schedule}

The objective function of the MILP model that maximizes the NPV of the mining operation can be formulated using the continuous decision variables $\left(y_{p}^{a, t}\right.$ and $\left.x_{k}^{u, t}\right)$ to model mining and processing requirements for all mining locations and processing destinations respectively. Using continuous decision variables allows for fractional extraction of mining-panels and mining-cuts in different periods for different locations and destinations. The objective function of the MILP model for maximizing the NPV of the mining operation is represented by Equation (7):

$\operatorname{Max} \sum_{a=1}^{A} \sum_{j=1}^{J} \sum_{u=1}^{U} \sum_{t=1}^{T}\left(\sum_{\substack{k \in B_{p} \\ p \in B_{j}}}\left(v_{k}^{u, t} \times x_{k}^{u, t}-b_{p}^{a, t} \times y_{p}^{a, t}\right)\right)$

The related constraints used in controlling the mining and processing targets are stated by Equations (8) to (13). They are defined in the form of an upper and lower bound and are controlled by the decision variables, $y_{p}^{a, t}$ and $x_{k}^{u, t}$. Equation (8) defines the mining capacity requirements while Equation (9) defines the processing capacity requirements. Since ore proce- ssing drives the optimization problem, the lower bound for the processing target is usually not defined. The production grade blending constraints control the grade of ore bitumen and ore fines in the mined material for all processing destinations. These constraints are formulated in Equations (10) to (13):

$$
\begin{aligned}
& T_{m, l b}^{a, t} \leq \sum_{j=1}^{J}\left(\sum_{p \in B_{j}}\left(o_{p}+d_{p}+n_{p}+w_{p}\right) \times y_{p}^{a, t}\right) \leq T_{m, u b}^{a, t} \\
& T_{p r, l b}^{u, t} \leq \sum_{p=1}^{P}\left(\sum_{k \in B_{p}}\left(o_{k} \times x_{k}^{u, t}\right)\right) \leq T_{p r, u b}^{u, t}
\end{aligned}
$$

$\sum_{p=1}^{P} \sum_{k \in B_{p}} g_{k}^{e} \times o_{k} \times x_{k}^{u, t}-\bar{g}^{u, t, e} \sum_{p=1}^{P} \sum_{k \in B_{p}} o_{k} \times x_{k}^{u, t} \leq 0$

$\sum_{p=1}^{P} \sum_{k \in B_{p}} g_{k}^{e} \times o_{k} \times x_{k}^{u, t}-\underline{g}^{u, t, e} \sum_{p=1}^{P} \sum_{k \in B_{p}} o_{k} \times x_{k}^{u, t} \geq 0$

$\sum_{p=1}^{P} \sum_{k \in B_{p}} f_{k}^{e} \times o_{k} \times x_{k}^{u, t}-\bar{f}^{u, t, e} \sum_{p=1}^{P} \sum_{k \in B_{p}} o_{k} \times x_{k}^{u, t} \leq 0$

$\sum_{p=1}^{P} \sum_{k \in B_{p}} f_{k}^{e} \times o_{k} \times x_{k}^{u, t}-\underline{f}^{u, t, e} \sum_{p=1}^{P} \sum_{k \in B_{p}} o_{k} \times x_{k}^{u, t} \geq 0$

\subsection{The MILP Model for Optimizing Dyke Material Schedule}

The objective function of the MILP model that minimizes the dyke construction cost as part of the waste management operation can be formulated using the continuous decision variables $z_{k}^{u, t}, c_{k}^{u, t}$, and $s_{k}^{u, t}$ to model OB, IB and TCS dyke material requirements respectively for all dyke construction destinations. The objective function for minimizing the dyke construction cost is represented by Equation (14):

$\operatorname{Min} \sum_{a=1}^{A} \sum_{j=1}^{J} \sum_{u=1}^{U} \sum_{t=1}^{T}\left(\sum_{\substack{k \in B_{p} \\ p \in B_{j}}}\left(p_{k}^{u, t} \times z_{k}^{u, t}+m_{k}^{u, t} \times c_{k}^{u, t}+h_{k}^{u, t} \times s_{k}^{u, t}\right)\right)$

The constraints used in controlling the OB, IB and TCS dyke material requirements are modeled with Equations (15) to (17) respectively. These define the upper and lower bounds and are controlled by the variables $z_{k}^{u, t}, c_{k}^{u, t}$, and $s_{k}^{u, t}$. Equations (18) and (19) are grade blending constraints which control the grade of interburden fines in the mined material for dyke construction destinations. These constraints ensure that the move- 
ment of dyke material and dyke construction scheduling can be well integrated with the mining fleet management plan:

$$
\begin{aligned}
& T_{d, l b}^{u, t} \leq \sum_{p=1}^{P}\left(\sum_{k \in B_{p}}\left(d_{k} \times z_{k}^{u, t}\right)\right) \leq T_{d, u b}^{u, t} \\
& T_{n, l b}^{u, t} \leq \sum_{p=1}^{P}\left(\sum_{k \in B_{p}}\left(n_{k} \times c_{k}^{u, t}\right)\right) \leq T_{n, u b}^{u, t} \\
& T_{l, l b}^{u, t} \leq \sum_{p=1}^{P}\left(\sum_{k \in B_{p}}\left(l_{k} \times s_{k}^{u, t}\right)\right) \leq T_{l, u b}^{u, t} \\
& \sum_{p=1}^{P} \sum_{k \in B_{p}} f_{k}^{d} \times n_{k} \times c_{k}^{u, t}-\bar{f}^{u, t, d} \sum_{p=1}^{P} \sum_{k \in B_{p}} n_{k} \times c_{k}^{u, t} \leq 0 \\
& \sum_{p=1}^{P} \sum_{k \in B_{p}} f_{k}^{d} \times n_{k} \times c_{k}^{u, t}-\underline{f}^{u, t, d} \sum_{p=1}^{P} \sum_{k \in B_{p}} n_{k} \times c_{k}^{u, t} \geq 0
\end{aligned}
$$

\subsection{The MILP Model for Optimizing In-pit Tailings Backfilling Schedule}

The objective function of the MILP model that maximizes the in-pit volume for tailings backfilling as part of the waste management strategy can be formulated using the continuous decision variable, $d_{j}^{a, t}$, to model the volume of mining phase backfilled in each period. A pseudo mining revenue per metre cube, $p s^{r e v}$, is defined to drive the backfilling operation. The continuous decision variable allows for fractional backfilling of a mining phase. This objective function can be represented by Equation (20):

$$
\operatorname{Max} \sum_{a=1}^{A} \sum_{j=1}^{J} \sum_{u=1}^{U} \sum_{t=1}^{T}\left(\sum_{\substack{k \in B_{p} \\ p \in B_{j}}}\left(p s_{j}^{r e v} \times d_{j}^{a, t}\right)\right)
$$

The constraint used in controlling the in-pit and ex-pit volume filled in each period is modeled with Equation (21). This defines the available in-pit volume in each mining phase to be backfilled, $v p_{j}$, and is controlled by variable $d_{j}^{a, t}$; the ex-pit volume, $e p^{u}$, to be filled and is controlled by variable $i^{a, u, t}$. This constraint cumulatively reconciles the in-pit and ex-pit volume available with the volume of tailings produced, $t s_{p}$, waste material mined, $w v_{p}$, overburden dyke material mined, $d v_{p}$, and interburden dyke material mined, $n v_{p}$, throughout the mine life:

$$
\begin{aligned}
& \sum_{j=1}^{J}\left(\sum_{p \in B_{j}}\left(v p_{j} \times d_{j}^{a, t}\right)\right)+\sum_{u=1}^{U}\left(e p^{u} \times i^{a, u, t}\right)-\sum_{j=1}^{J}\left(\sum _ { p \in B _ { j } } \left(t s_{p}+w v_{p}\right.\right. \\
& \left.\left.+d v_{p}+n v_{p}\right)\right)=0
\end{aligned}
$$

\subsection{The MILP Model General Constraints}

The general constraints that apply to all the MILP models discussed relate to the mining precedence and the logics of the variables during optimization. These have been documented in Ben-Awuah et al. (2012) and Ben-Awuah and Askari-Nasab (2013). These constraints include:

a) Vertical mining precedence: all the immediate predecessor mining-panels above the current mining-panel should be extracted prior to extracting the current mining-panel.

b) Horizontal mining precedence: all the immediate predecessor mining-panels preceding the current mining-panel in the horizontal mining direction are extracted before or together with the current mining-panel. These are referred to as absolute and concurrent precedences respectively.

c) Tailings cells precedence: all the mining phases within the immediate predecessor tailings cell that precedes the current tailings cell are extracted before extraction of the mining phases in the current tailings cell.

d) Variables logic control: the logic of the mining, processing, dyke material and backfilling variables with regards to their limits and definitions are within acceptable ranges.

\section{Modeling the IOSMP Problem}

The IOSMP problem is modeled in Evaluator as a multimine, multi-destination and multi-material type optimization problem. A schematic diagram of the scheduling project network can be seen in Figure 2. The conceptual mining and waste management model applied here is similar to that presented in Ben-Awuah et al. (2012). This includes completely extracting all material in the current tailings cell prior to mining the next tailings cell in the direction of mining. This makes the current tailings cell available for in-pit tailings deposition. The IOSMP problem was modeled with four mines namely; Pit, DykeMat, BackFill and ExWaste (Figure 2). The Pit node contains all the data relating to the mining-cuts and mining panels to be extracted. The DykeMat node contains the quantity of OB, IB and TCS dyke material required to construct the designed dykes. The dyke locations are fixed prior to each optimization. The BackFill node contains the volume of the mine phases that becomes available as mining proceeds in the defined direction for subsequent backfilling. The ExWaste node contains the available volume at the external waste facility.

Material from the pit can be sent to the processing plant, dyke construction destinations or waste dump based on the material type and mine economics. Material sent to the processing plant results in a product that generates revenue for the mining project. Material sent for dyke construction can be sent to either of the dyke destinations depending on which dyke is immedia- 
tely needed and has the minimum cost. Material that does not qualify for processing or dyke construction is sent to the waste dump. Material that qualifies for building dykes but is not needed for construction at any point in time will be sent to the waste dump as well. The constraints that are set up to control the pit mining are mainly the mining capacity, processing limits and the ore quality requirements throughout the mine life. The vertical and horizontal mining sequences for the mining-panels which include both absolute and concurrent precedences are defined as well. Complete extraction of the in-pit ore is enforced as required by oil sands mining regulations.

The DykeMat node which contains the designed dyke construction requirements is modeled to send a request for dyke material anytime a dyke needs to be built at a specified location. This request specifies the dyke material type and quantity required. This is done through a constraint which ensures that the dyke material request emanating from DykeMat is equal to the dyke material flowing from the Pit through the DykeM node to the appropriate dyke construction destination. The corresponding destination specific dyke construction cost is then applied.

The request to construct a dyke is issued by the BackFill node. The backfilling activity has been modeled to generate a pseudo revenue for every metre cube backfilled. As mining proceeds in the defined mining direction, once the mining phases making up the first tailings cell are completely extracted, a request for dyke construction material is placed and then subsequently backfilling starts. The model features a constraint which cumulatively reconciles the in-pit and ex-pit volume available with the volume of tailings produced, dyke material placed and waste material mined throughout the mine life. Dyke construction proceeds simultaneously with backfilling until the dyke is fully built and the corresponding tailings cell completely filled. Continuous backfilling is enforced such that once in-pit backfilling starts, this activity must continue until the end of the mine life. This ensures that the installed backfilling pumping or trucking capacity is fully utilized. Any excess waste material is sent to the external waste facility.

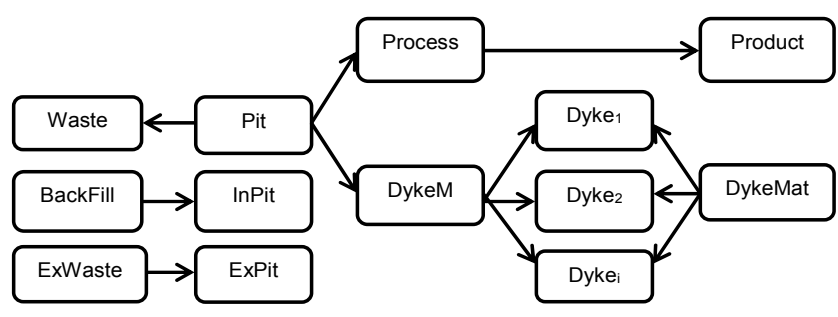

Figure 2. Schematic diagram of the project scheduling network.

\section{Case Study: Results and Discussions}

The MILP model for the IOSMP problem was implemented on an oil sands deposit with a final pit covering an area of about 3,000 ha. The mineralized zone of this deposit occurs in the McMurray formations. The deposit is to be scheduled for 20 periods for the processing plant with an integrated waste mana- gement strategy that includes dyke construction and an in-pit tailings disposal scheme. The performance of the proposed MILP model was analyzed based on NPV, mining production targets, smoothness and practicality of the generated schedules and the availability of tailings containment areas. Table 1 provides information about the orebody model within the ultimate pit limit used in the case study. The area to be mined is divided into 15 pushbacks with each holding approximately equal tonnes of material. These pushbacks enable the creation of practical mining-panels to be used in controlling the mining operation. In consultation with tailings dam engineers based on required tailings cell capacities, three scenarios of tailings disposal strategies will be investigated. This relates to the number and location of dykes to be constructed and their impact on the mining operation. The waste management scenarios to be investigated include tailings disposal strategies with four, three and two tailings cells.

Table 1. Oil Sands Deposit Characteristics

\begin{tabular}{ll}
\hline Characteristic & Value \\
\hline Tonnage of rock $(\mathrm{Mt})$ & 6,263 \\
Ore tonnage (Mt) & 1,923 \\
OB dyke material tonnage (Mt) & 1,866 \\
IB dyke material tonnage (Mt) & 1,873 \\
TCS dyke material tonnage (Mt) & 1,350 \\
Waste tonnage (Mt) & 601 \\
Average ore bitumen grade (wt $\%)$ & 13.3 \\
Average ore fines (wt $\%)$ & 18.1 \\
Number of blocks & 81,760 \\
Number of mining-cuts & 1,773 \\
Number of mining-panels & 123 \\
Block dimensions $\left(\mathrm{m}^{3}\right)$ & $50 \times 50 \times 15$ \\
Number of benches & 9 \\
\hline
\end{tabular}

Table 2. Mining and Processing Targets, OB, IB and TCS Dyke Construction Requirements and Ore Grade Limits for the MILP Model

\begin{tabular}{ll}
\hline Production scheduling parameter & Value \\
\hline Mining target (Mt) & $350 / 0$ \\
Processing target (Mt) & $120 / 0$ \\
Average ore bitumen grade (wt $\%)$ & $16 / 7$ \\
Average ore fines (wt $\%$ ) & $30 / 0$ \\
OB dyke material tonnage required per dyke (Mt) & 4.5 \\
IB dyke material tonnage required per dyke (Mt) & 4.5 \\
TCS dyke material tonnage required per dyke (Mt) & 220 \\
\hline
\end{tabular}

A hierarchical clustering algorithm is used in clustering blocks within each pushback into mining-cuts (Tabesh and AskariNasab, 2011). Clustering blocks into mining-cuts ensures the MILP scheduler generates a mining strategy at a selective mining unit that is practical from mining operation perspective. In solving the MILP model with Gurobi, the absolute tolerance on 
the gap between the best integer objective and the objective of the best node remaining in the branch and cut algorithm, referred to as MIPGap, was set at $2 \%$ for the optimization of the mining project. The controls for the mining capacity $\left(T_{m, u b}^{a, t} / T_{m, l b}^{a, t}\right)$, processing plant feed $\left(T_{p r, u b}^{u, t} / T_{p r, l b}^{u, t}\right)$, dyke construction requirements, bitumen grade $\left({ }_{g}^{-u, t, e} / g^{u, t, e}\right)$ and fines percent $\left(\bar{f}^{u, t, e} / f^{u, t, e}\right)$ have been summarized in Table 2. Mining will proceed from pushback 1 to 15 with complete extraction of each tailings cell prior to the next. In addition to the processing plant, tailings backfilling activities and dyke construction requirements will be scheduled. Backfilling of the last tailings cell prior to the end of the mine life is not started since ore processing is assumed to have been completed. Details of the waste management strategy implemented here has been documented by Ben-A-wuah et al. (2012).

Table 3. Summary of Results for the IOSMP Problem with Different Waste Disposal Strategies

\begin{tabular}{llll}
\hline Scenario \# & 1 & 2 & 3 \\
\hline Tonnage mined (Mt) & 6,217 & 6,211 & 6,201 \\
Ore Tonnage (Mt) & 1,923 & 1,923 & 1,923 \\
Dyke material tonnage (Mt) & 687 & 458 & 229 \\
NPV (M\$) & 25,211 & 25,363 & 27,262 \\
Dyke construction cost (M\$) & 232 & 154 & 68 \\
Pseudo backfilled revenue (M\$) & 1,405 & 1,175 & 820 \\
No. of tailings cells & 4 & 3 & 2 \\
In-pit volume backfilled (\%) & 81 & 67 & 54 \\
MIPGap (\%) & 1.5 & 1.8 & 2 \\
\hline
\end{tabular}

\subsection{Analysis}

The experiment was carried out on three scenarios of the IOSMP problem with varying waste management strategies at a $10 \%$ discount rate. Scenario 1 (Table 3) was chosen for discussions due to its relatively efficient waste management strategy which uses about $80 \%$ of the in-pit volume before the end of mine life. After optimization, the NPV generated is $\$ 25,211 \mathrm{M}$ at a $1.5 \%$ MIPGap. This excludes the dyke construction cost for all tailings cells and the pseudo revenue from backfilling. The total dyke construction cost is $\$ 232 \mathrm{M}$ and the total pseudo revenue from backfilling is $\$ 1,405 \mathrm{M}$. The scenario implemented here focuses on a practically integrated oil sands production planning and waste management strategy that generates value and is sustainable. This includes mining in a specified direction and making completely extracted tailings cells available for inpit dyke construction and subsequently tailings deposition. This reduces the environmental footprints of the external tailings facility by commissioning in-pit tailings facilities on time. The mining direction was decided on during an initial production schedule run in Whittle (Gemcom Software International Inc., 2012). The mining direction with the best NPV was selected for the MILP model. The mining sequence at level $305 \mathrm{~m}$ for all pushbacks with a west-east mining direction and tailings cells dyke locations in Scenario 1 can be seen in Figure 3. Figure 3 also shows the complete extraction of each tailings cell prior to mining the next, to support tailings management. The mining sequence shows a progressive continuous mining in the specified direction to ensure least mobility and increased utilization of loading equipment. This is very important in the case of oil sands mining where large cable shovels are used. The size of the mining-cuts and mining-panels also enables good equipment maneuverability and supports multiple material loading operations. It enables mining to proceed with a reduced number of required drop-cuts.

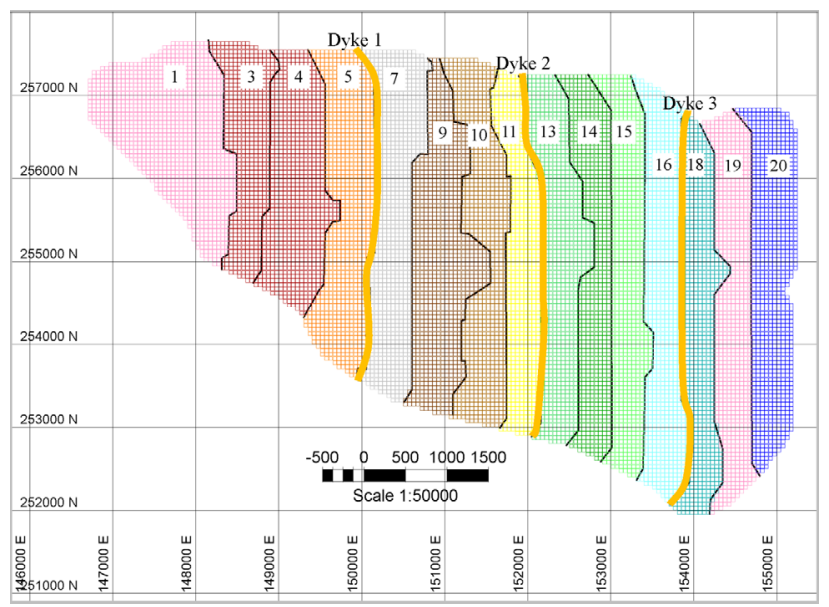

Figure 3. Scenario 1 mining sequence at level $305 \mathrm{~m}$ with a west-east mining direction and dyke locations for tailings cells.

Figure 4 illustrates how mining and processing progress uniformly throughout the mine life. This ensures efficient utilization of the mining fleet and processing plant capacity. Prestripping of pushbacks 1 and 2 start in the first and second years, resulting in less ore being mined. Subsequently, uniform ore feed is provided at the required processing plant capacity throughout the mine life with a capacity step-down in year 17 . The type and quantity of dyke material needed to build the in-pit tailings cells dykes in a timely manner and at a minimum cost can be seen in Figure 5. The request for dyke material is made anytime all the pushbacks in a tailings cell are completely mined and backfilling operations are ready to take off. At that time, the dyke material mined is sent to the scheduled dyke construction destination. By design the $\mathrm{OB}$ and IB dyke material are initially required to construct the dyke foundation and then subsequently TCS dyke material is needed for the main dyke. The tailings backfilling schedule is shown in Figure 6. This shows that at a continuous backfilling rate of about $140 \mathrm{Mm}^{3}$ per year, tailings cell 1 is filled from periods 6 to 11 . Tailings cell 2 is filled from periods 12 to 16 at a rate of about $160 \mathrm{Mm}^{3}$ per year while tailings cell 3 is filled from period 17 to 20 at a rate of about $190 \mathrm{Mm}^{3}$. These backfilling variations are as a result of enforcing continuous backfilling and the volume of tailings, dyke material and waste available for backfilling. After the dyke foundation construction with overburden and interburden (OI) dyke material, the backfilling operation occurs simultaneously as the main tailings cell dyke is being constructed with TCS 
dyke material. This operation is usually undertaken with a hydrocyclone that places the TCS dyke material on the dyke and the tailings slurry inside the cell. Table 3 shows the total material mined, ore, OB and IB dyke material tonnage mined and TCS dyke material tonnage placed from the processing plant. The schedules give the planner good control over production forecasting and provides a robust platform for effective dyke construction planning and tailings storage management.

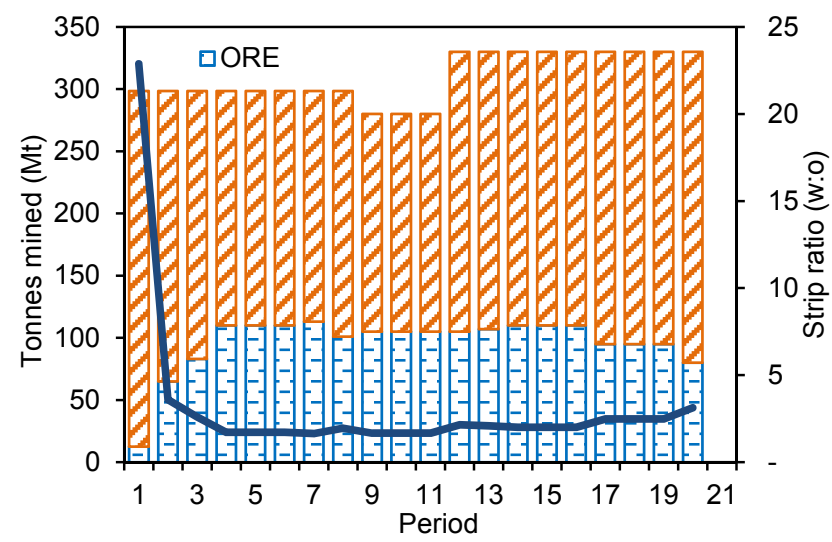

Figure 4. Production schedule for ore and waste, and stripping ratio.

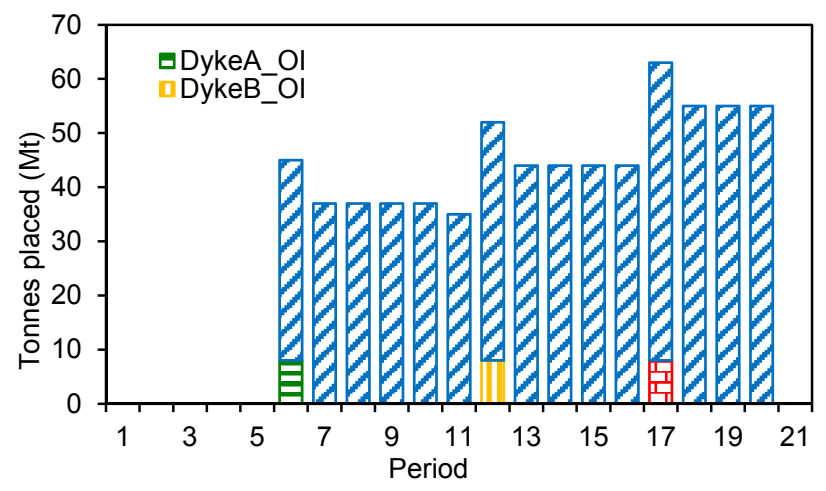

Figure 5. Dyke material schedule including OB, IB and TCS for Dykes 1, 2 and 3.

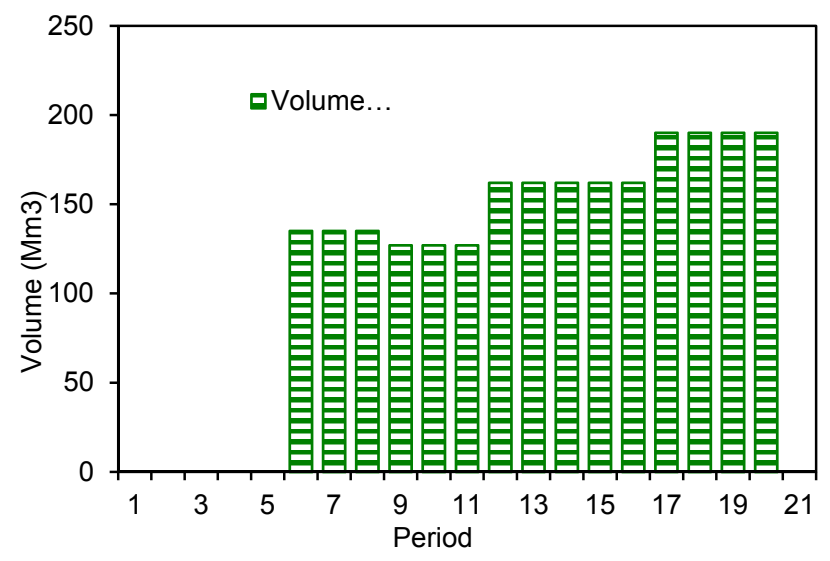

Figure 6. Backfilling schedule for in-pit tailings cells.
The ore and dyke material quality is obtained by blending the run-of-mine material. The targeted processing plant head grade was successfully achieved in all periods. It was targeted to reduce the periodic grade variability by setting tighter lower and upper grade bounds. The periodic grades in each pushback can be varied depending on the processing plant or dyke construction requirements while ensuring a feasible solution is obtained. Figures 7 and 8 show the average ore bitumen grades and ore fines percent over the mine life.

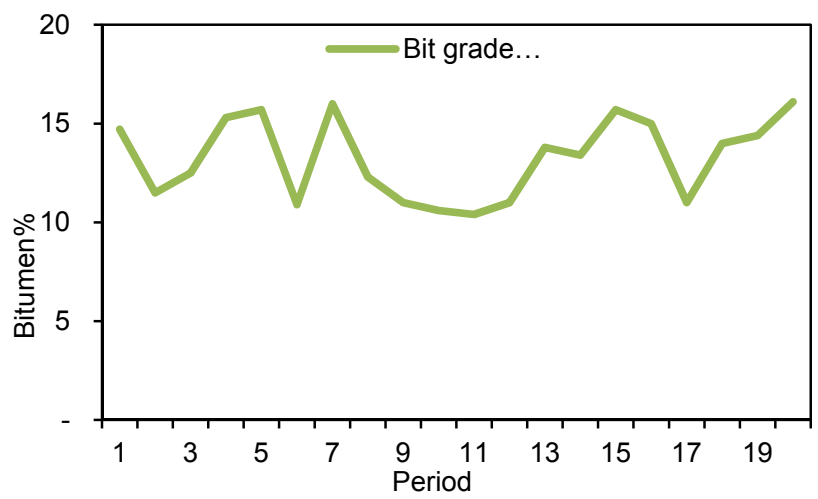

Figure 7. Average ore bitumen grades.

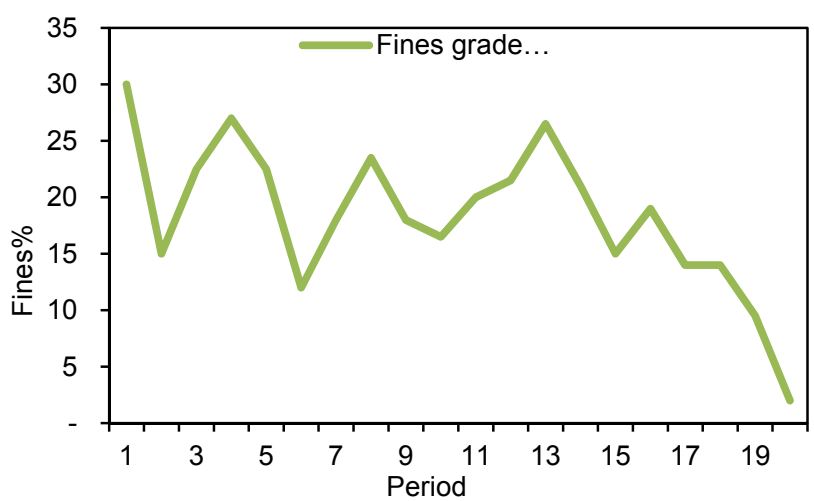

Figure 8. Average ore fines percent.

\subsection{Comparison}

In implementing the MILP model for the IOSMP problem, three optimization scenarios were executed to assess the effect of different waste disposal strategies on the mining operation in terms of NPV and waste management cost. Table 3 shows a summary of the results of the scenarios with different number of dykes and tailings cells. The results show that Scenario 1 has the lowest NPV, highest dyke construction cost and highest pseudo backfilling revenue. This is due to the fact that with more tailings cells, the production operation is more restricted as each tailings cell must be completely exhausted before mining in the next tailings cell commences. The reduced operational flexibility also comes from the decrease in the size of the tailings cells thereby restricting the optimizer when generating the mining schedules. More tailings cells also mean more dykes being constructed to hold the tailings thereby increasing dyke construc- 
tion cost. However, this strategy also leads to the availability of in-pit tailings disposal areas quite early in the mine life. This results in an increase in the pseudo revenue from the backfilling operation which in real terms is savings in not sending the tailings to an external tailings facility at a higher cost. The scenario with the least number of tailings cells (Scenario 3) generates the highest NPV due to production scheduling flexibility and a corresponding reduced dyke construction cost. This strategy on the other hand results in delayed in-pit tailings deposition leading to reduced pseudo backfilling revenue. It is also noted that the unfilled tailings cell size at the end of the mine life for Scenario 1 is $571 \mathrm{Mm}^{3}$ (19\%) compared to $968 \mathrm{Mm}^{3}$ (33\%) for Scenario 2 and 1,336 $\mathrm{Mm}^{3}$ (46\%) for Scenario 3 .

These three different waste management strategies have their own inherent advantages and disadvantages depending on conditions at the mine and priorities of the operation. If in-pit tailings deposition must happen soon as part of an environmental policy, reclamation plan or limited immediate availability of an external tailings facility capacity, then Scenario 1 may be preferred. If on the other hand, there is the need to increase NPV and delay in-pit deposition due to availability of capacity at an external tailings facility, then Scenario 3 may be preferred. Another strategy between these two relatively extreme scenarios (Scenario 2) can be considered as well as a hybridized approach which may include lateral splitting of the in-pit area to reduce the unfilled tailings cell size remaining at the end of the operation.

\section{Conclusions}

The integrated oil sands mine planning problem involves the incorporation of waste management into the production planning process in an optimization framework that maximizes value and is sustainable. This research developed, implemented and verified a MILP formulation which takes into account practical shovel movements by selecting mining-panels and miningcuts that are comparable to the selective mining units of oil sands mining operations. Different waste management techniques ranging from having two in-pit tailings cells to four in-pit tailings cells have been presented for the MILP model. The model generated a practical, smooth and uniform schedule for ore and in-pit tailings disposal. The schedule gives the planner good control over dyke material and provides a robust platform for effective dyke construction and waste disposal planning.

The results show that increasing the number of in-pit tailings cells reduces the NPV of the operation as a result of a reduced operational flexibility. The reduced operational flexibility comes from the decrease in the size of the tailings cells thereby restricting the optimizer when generating the mining schedules. However, this strategy apart from making in-pit tailings storage areas available early in the mine life, also makes an efficient use of in-pit storage areas which are required for sustainable operations and timely reclamation. This framework for the IOSMP problem results in solutions within known limits of optimization. In general, this integrated mine planning framework can be implemented for various directions of mining, different shapes and sizes of tailings cells, multiple mine pits and phases configurations and final landscape designs.

The total NPV generated for Scenario 1 excluding dyke construction and pseudo backfilling revenue for all tailings cells is $\$ 25,211 \mathrm{M}$. The total dyke construction cost is $\$ 232 \mathrm{M}$ and the total pseudo revenue from backfilling is $\$ 1,405 \mathrm{M}$. The average bitumen grade and fines percent for the scheduled ore was $13.3 \%$ and $18.1 \%$ respectively. The total material mined was 6,217 Mt, which includes: 1,923 Mt of ore, $27 \mathrm{Mt}$ of OB and IB dyke material, while $660 \mathrm{Mt}$ of TCS dyke material was placed.

\section{References}

Akaike, A., and Dagdelen, K. (1999). A strategic production scheduling method for an open pit mine, Proc. of the 28th International Symposium on the Application of Computers and Operations Research in the Mineral Industry, Littleton, USA, pp. 729-738.

Askari-Nasab, H., Awuah-Offei, K., and Eivazy, H. (2010). Large-scale open pit production scheduling using mixed integer linear programming. Int. J. Min. Miner. Eng., 2(3), 185-214. doi: 10.1504/IJM ME.2010.037624

Askari-Nasab, H., and Ben-Awuah, E. (2011). Integration of oil sands mine planning and waste management using goal programming, $P$ roc. of the 35th International Symposium on the Application of Computers and Operations Research in the Mineral Industry, Wollongong, Australia, pp. 329-350.

Askari-Nasab, H., Pourrahimian, Y., Ben-Awuah, E., and Kalantari, S. (2011). Mixed integer linear programming formulations for open pit production scheduling. J. Min. Sci., 47(3), 338-359. doi: 10.1134/s1 062739147030117

Ben-Awuah, E. (2013). Oil Sands Mine Planning and Waste Management, Ph.D. Dissertation, Department of Civil and Environmental Engineering, University of Alberta, Edmonton, Canada.

Ben-Awuah, E., and Askari-Nasab, H. (2011). Oil sands mine planning and waste management using mixed integer goal programming. Int. J. Min. Reclam. Environ., 25(3), 226-247. doi: 10.1080/17480930.2 010.549656

Ben-Awuah, E., and Askari-Nasab, H. (2013). Incorporating waste management into oil sands long term production planning. Inst. Mining Metall. Trans. Sect. A. Mining Technol., 122(1), 33-45. doi: 10.1179 /1743286312Y.0000000031

Ben-Awuah, E., Askari-Nasab, H., and Awuah-Offei, K. (2012). Production scheduling and waste disposal planning for oil sands mining using goal programming. J. Environ. Inf., 20(1), 20-33. doi: 10.3808 /jei.201200217

Caccetta, L., and Hill, S. P. (2003). An application of branch and cut to open pit mine scheduling. J. Global Optimiz., 27(2-3), 349-365. doi: 10.1023/A:1024835022186

Chanda, E. K. C., and Dagdelen, K. (1995). Optimal blending of mine production using goal programming and interactive graphics systems. Int. J. Min. Reclam. Environ., 9(4), 203-208. doi: 10.1080/092 08119508964748

Dagdelen, K. (1985). Optimum Multi-period Open Pit Mine Production Scheduling by Lagrangian Parameterization, Ph.D. Dissertation, University of Colorado, Colorado, USA.

Dilay, J. D. (2001). Interim Directive ID 2001-7, Calgary, Alberta Energy and Utilities Board, Alberta, Canada.

Esfandiri, B., Aryanezhad, M. B., and Abrishamifar, S. A. (2004). Open pit optimization including mineral dressing criteria using $0-1$ 
non-linear goal programming. Inst. Mining Metall. Trans. Sect. A. Mining Technol., 113(1), 3-16.

Gemcom Software International Inc. (2012). Whittle strategic mine planning software, Ver. 4.4, Vancouver.

Gershon, M. E. (1983). Optimal mine production scheduling: evaluation of large scale mathematical programming approaches. Int. J. Mining Eng., 1(4), 315-329. doi: 10.1007/BF00881548

Gurobi Optimization (2013). Gurobi, Ver. 5.5, Houston.

Hannan, E. L. (1985). An assessment of some criticisms of goal programming. Comput. Oper. Res., 12(6), 525-541. doi: 10.1016/03050 $548(85) 90052-8$

Johnson, T. B. (1969). Optimum open-pit mine production scheduling, Proc. of the 8th International Symposium on the Application of Computers and Operations Research in the Mineral Industry, Utah, USA, pp. 539-562.

Masliyah, J. (2010). Fundamentals of Oil Sands Extraction, Edmonton, University of Alberta.

McFadyen, D. (2008). Directive 074, Calgary, Energy Resources Conservation Board, Canada.
Ramazan, S. (2001). Open Pit Mine Scheduling Based on Fundamental Tree Algorithm, Ph.D. Dissertation, Colorado School of Mines, Colorado, USA.

Ramazan, S., and Dimitrakopoulos, R. (2004). Recent applications of operations research and efficient MIP formulations in open pit mining, Proc. of the SME Annual Meeting, Cincinnati, Ohio, USA, pp. 73-78.

Snowden Mining Industry Consultants (2013). Evaluator, V18, Perth. Tabesh, M., and Askari-Nasab, H. (2011). Two stage clustering algorithm for block aggregation in open pit mines. Inst. Mining Metall. Trans. Sect. A. Mining Technol., 120(3), 158-169. doi: 10.1179/1743 286311y.0000000009

Zeleny, M. (1980). Multiple objectives in mathematical programming: Letting the man in. Comput. Oper. Res., 7(1-2), 1-4. doi: 10.1016/03 05-0548(80)90010-6

Zhang, Y. D., Cheng, Y. P., and Su, J. (1993). Application of goal programming in open pit planning. Int. J. Min. Reclam. Environ., 7(1), 41-45. doi: 10.1080/09208119308964683 